\title{
Anterior Urethroplasty for Urethral Stricture and Subsequent Erectile Dysfunction. Correlations and Treatments in the Literature
}

ISSN: 2578-0093

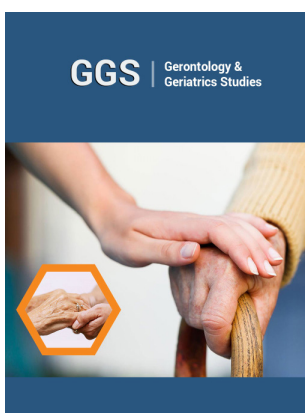

*Corresponding author: Fiorello N, Division of Urology, Italy

Submission: 海 May 27, 2019

Published: 海August 26, 2019

Volume 5 - Issue 1

How to cite this article: Fiorello $\mathrm{N}$ Jallous H, Porru D, Marchetti C, Giliberto $\mathrm{GL}$, et al. Anterior Urethroplasty for Urethral Stricture and Subsequent Erectile Dysfunction. Correlations and Treatments in the Literature. Gerontol \& Geriatric stud.5(1). GGS.000602.2019.

DOI: 10.31031/GGS.2019.05.000602

Copyright@ Fiorello N, This article is distributed under the terms of the Creative Commons Attribution 4.0 International License, which permits unrestricted use and redistribution provided that the original author and source are credited.

\author{
Fiorello $\mathrm{N}^{1 *}$, Jallous $\mathrm{H}^{1}$, Porru $\mathrm{D}^{1}$, Marchetti $\mathrm{C}^{1}$, Giliberto $\mathrm{GL}^{1}$, Regina $\mathrm{C}^{1}$, \\ Ringressi $\mathrm{A}^{1}$, Cebrelli $\mathrm{T}^{1}$ and Simeone $\mathrm{C}^{2}$ \\ ${ }^{1}$ Division of Urology, Italy \\ ${ }^{2}$ University Hospital Spedali Civili, Italy
}

Abstract

Abbreviations: ED: Erectile Dysfunction; IIEF: International Index of Erectile Function

\section{Introduction}

Urethroplasty is the gold standard for treatment of urethral stricture disease [1]. Potential risk of erectile dysfunction (ED) after urethroplasty procedures is thought to be attributable to cavernous and perineal nerve injury, or to the disruption of bulbar artery flow [2]. Before making a treatment decision for patients presenting with a urethral stricture, following anamnesis and general examinations, appropriate diagnostics are necessary. This includes at least uroflowmetry and cystourethrography and the use of ultrasound and cystoscopy may be of additional help [3]. There are many techniques described in the literature and the recurrence of ED in the first postoperative period is common. The objective of study is analyzing the data in the literature and the treatments for de novo ED.

\section{Surgical techniques}

In the bulbar urethra, the choice of surgical techniques depends on the stricture length. Stricture excision and primary re-anastomosis are considered an appropriate procedure for short strictures within $2 \mathrm{~cm}$. For strictures $3-5 \mathrm{~cm}$ or longer, augmented roof-strip anastomosis and substitution urethroplasty are recommended [4]. Substitution urethroplasty is commonly performed to deal with long or complex strictures. In carrying out this procedure, the substitution tissue should possess a thick epithelial layer, minimal donor site morbidities and be easy to procure [5]. Currently, alternative replacement tissues include scrotal skin [6], penile skin [7], bladder epithelium [8], colonic mucosa [9], and buccal and lingual mucosa [10]. One-staged urethroplasty using a buccal mucosa graft has been reported to achieve a high success rate. Nonetheless, when dealing with a more complex stricture or cases with adverse local conditions, a staged procedure is more commonly recommended [11].

\section{Post-operative}

In a prospective analysis of Erickson et al. [2]. anterior urethroplasty has been shown to negatively impact erectile function. 52 patients were enrolled in this prospective study and they were undergoing anterior urethroplasty between October 2006 and May 2008, monitoring the effects of urethroplasty on erectile function. The International Index of Erectile Function (IIEF) was completed preoperatively and on all subsequent postoperative visits. Preoperative and postoperative erectile function was compared. Postoperative erectile dysfunction was noted in $20(38 \%)$ men, of whom 18 recovered fully at a mean postoperative period of 190 days (range 92 to 398).

In patients with normal preoperative erectile function bulbar urethroplasty was more likely than penile urethroplasty to cause erectile dysfunction [2]. In another prospective analysis of Dogra et al. [12] it was evaluated the incidence and probability of recovery of erectile dysfunction after different types of one-stage urethroplasty for anterior urethral stricture disease. Mean preoperative IIEF score was 24.60-2.365, which was similar among 
the three groups. ED after urethroplasty was found in 4/25(16\%), $9 / 32(28 \%)$, and $2 / 21(10 \%)$ in groups 1,2 , and 3, respectively. In that study, it was found that although bulbar anastomotic urethroplasty causes more decline in IIEF score postoperatively, overall there is no difference among the type of repair. Recovery of EF occurred in more than $96 \%$ of cases within 6 months of urethroplasty $[13,14]$ has published another study sexual dysfunction after Urethroplasty, reporting the differences between the different types of techniques. Treatment of post urethroplasty erectile dysfunction is similar to that of other causes of erectile dysfunction.

PDE5Is, which are the current first-line treatment of erectile dysfunction, have been tried in post urethroplasty setting. Most patients with anterior urethroplasty erectile dysfunction responded to PDE5Is. In this study the effectiveness was been tried also in posterior urethroplasty, performed for urethral damage from trauma of the pelvic district. For posterior urethroplasty treatment success depends on the etiology of erectile dysfunction, with a $60 \%$ improvement for neurogenic causes and $20 \%$ for arthritogenic causes, and an overall response rate of $47 \%$ to $80 \%$. If they fail, intracorneal injection can be used with a $100 \%$ success rate in neurogenic causes and an approximately $50 \%$ success rate in arthritogenic causes of erectile dysfunction [14]. In a meta-analysis of Blaschko et al. [15] it was evaluating the likelihood of developing de novo erectile dysfunction after anterior urethroplasty and to determine if this likelihood is influenced by age, stricture length, number of previous procedures or timing of evaluation.

Thirty-six articles with 2323 total patients who underwent anterior urethroplasty procedures met the inclusion criteria for meta-analysis. The incidence of post-urethroplasty de novo ED ranged from 0 to $38 \%$. This meta-analysis found that de novo ED was rare, with an incidence of 1\%. The five studies that reported a de novo post-urethroplasty ED incidence of $>20 \%$ were all conducted after 2001, all used a questionnaire to assess ED, and all patients were directly questioned about ED postoperatively. In many cases de novo ED resolved 6-12 months after surgery. Seven of the 21 studies that reported de novo ED reported resolution of ED in $86 \%(50 / 58)$ of cases [14].

\section{Conclusions}

ED can be a complication of anterior urethroplasty due to an intraoperative damage caused to the nerve fibers involved in the erection. However, in many cases de novo ED resolved 6-12 months after surgery or, as shown in some studies, resolved after transient therapy with PDE5Is. Another study of Trevor Haines suggests improving ED recovery with psychological support therapy [15]. Urethral stricture remains the main indication for urethroplasty and ED may be considered a transient and acceptable complication.

\section{References}

1. Lue TF, Zeineh SJ, Schmidt RA, Tanagho EA (1984) Neuroanatomy of penile erection: Its relevance to iatrogenic impotence. J Urol 131(3): 273-280.

2. Erickson BA, Granieri MA, Meeks JJ, Cashy JP, Gonzalez CM, et al. (2010) Prospective analysis of erectile dysfunction after anterior urethroplasty: incidence and recovery of function. J Urol 183(2): 657-661.

3. Lumen N, Hoebeke P, Willemsen P, Troyer B, Pieters R, et al. (2009) Etiology of urethral stricture disease in the $21^{\text {st }}$ century. J Urol 182(3): 983-987.

4. Barbagli G, Sansalone S, Djinovic G, Romano G, Lazzeri M, et al. (2012) Current controversies in reconstructive surgery of the anterior urethra: A clinical overview. Int Braz J Urol 38(3): 307-316.

5. Wessells H, Aninch JW (1998) Current controversies in anterior urethral stricture repair: Free-graft versus pedicled skin-flap reconstruction. World J Urol 16(3): 175-180.

6. Jordan GH (2002) Scrotal and perineal flaps for anterior urethral reconstruction. Urol Clin North Am 29(2): 411-416.

7. Vyas PR, Roth DR, Perlmutter AD (1987) Experience with free grafts in urethral reconstruction. J Urol 137(3): 471-474.

8. Kinkead TM, Borzi PA, Duffy PG, Ransley PG (1994) Long-term follow up of bladder mucosa graft for male urethral reconstruction. J Urol 151(4): 1056-1058.

9. Xu YM, Qiao Y, Sa YL, Zhang J, Fu Q, et al. (2009) Urethral reconstruction using colonic mucosa graft for complex strictures. J Urol 182(3): 10401043.

10. Bhargava S, Patterson JM, Inman RD, Neil SM, Chapple CR, et al. (2008) Tissue-engineered buccal mucosa urethroplasty-clinical outcomes. Eur Urol 53(6): 1263-1269.

11. Palminteri E, Lazzeri M, Guazzoni G, Turini D, Barbagli G, et al. (2002) New 2-stage buccal mucosal graft urethroplasty. J Urol 167(1): 130-132.

12. Dogra PN, Ashish KS, Amlesh S (2011) Erectile dysfunction after anterior urethroplasty: A prospective analysis of incidence and probability of recovery-single-center experience. Urology 78(1): 78-81.

13. Dogra PN, Singh P, Nayyar R, Yadav S (2017) Sexual dysfunction after urethroplasty. Urol Clin North Am 44(1): 49-56.

14. Blaschko SD, Sanford MT, Cinman NM, McAninch JW, Breyer BN, et al. (2013) De novo erectile dysfunction after anterior urethroplasty: A systematic review and meta-analysis. BJU Int 112(5): 655-663.

15. HainesT, RourkeKF (2017) The effect of urethral transection on erectile function after anterior urethroplasty. World J Urol 35(5): 839-845. 